\title{
BASILIO DE SALAZAR, UN PINTOR DEL SIGLO XVII
}

\section{Por Xavier Moyssén}

Mucho es lo que aún falta por estudiar sobre la pintura de la Nueva España, si no es que aún está en espera de que se le estudie. Después de los trabajos de Manuel Toussaint, Francisco Pérez Salazar, Abelardo Carrillo y Gariel y Francisco de la Maza, nada semejante se ha publicado en los últimos años; esto no implica de ninguna manera, que se deba continuar publicando trabajos como los que ellos realizaron; todo lo contrario, cualquier estudio que hoy se haga tendrá que ser enfocado bajo otras exigencias críticas, pero que supere la situación que ellos dejaron. Los artistas y sus obras deberán ser vistos con novedosos métodos de interpretación y análisis, acordes a las corrientes estéticas actuales. Es necesaria, entre otras actividades, una minuciosa labor de investigación en los archivos, de preferencia en los de notarías, pues allí deben existir los contratos de obras o los testamentos de los pintores, casi siempre pródigos en noticias personales. La investigación en los archivos debe ofrecer nuevas noticias, pues no es posible más, el continuar repitiendo lo que años atrás dieron a conocer los autores arriba citados.

Un nuevo estudio sobre la pintura novoespañola y sus creadores, debe hacerse con un conocimiento autorizado de la pintura española, en primer lugar, mas sin olvidar otras escuelas europeas como la flamenca, la italiana y la francesa, presentes por varios conductos, desde la lámina impresa hasta la réplica de un cuadro de un afamado maestro; cito como ejemplo La crucifixión de San Pedro, existente en la iglesia franciscana de Xochimilco, copia evidente, si bien mediocre, de la famosa obra del Caravaggio. Con un criterio autorizado es posible establecer cuáles son las relaciones ciertas que guarda esta pintura respecto a la española de los siglos Xvi, xvir y xvirr. Al parecer la pintura virreinal no guarda dependencia alguna con la que se producía en la corte madrileña; ¿en dónde están, pues, sus conexiones con la pintura regional de la península; con la de la escuela valenciana y el tenebrismo de la misma representado por Francisco de Ribalta? $O$ con las escuelas locales andaluzas como la granadina, la sevillana, o la cordobesa, para no citar sino a los núcleos más conocidos. Y lo mismo se puede decir con relación a los maestros flamencos y su influencia; máxime que aquí 
trabajaron algunos pintores de esa nacionalidad. Se habla mucho de la presencia de Rubens, mas no se han establecido de manera convincente, los canales por los cuales llegó su influencia; aparte de los grabados de sus obras ¿hubo aquí cuadros suyos o de sus seguidores?; ésta es una pregunta que se antoja hacer, aunque es probable que no encuentre respuesta.

Entre las tareas a desarrollar para ese futuro estudio del arte pictórico virreinal, está la de establecer inventarios sobre la obra de cada artista, fotografiándola como condición indispensable. Una investigación paciente y minuciosa habrá de entregar muchas sorpresas, contenidas hoy en los cuadros que encierran los museos, las iglesias y las colecciones particulares. Los inventarios si se llevan a efecto deberán partir de una exigencia técnica que registre, entre otras cosas, los temas iconográficos, las técnicas empleadas; medida métrica de las obras, registro de las firmas, fecha de factura y lugar donde se encuentran los cuadros. Todo ello contribuirá a formar un criterio valorativo para armar un catálogo con las obras originales de los maestros y las que les son atribuidas sin base cierta, bien provenientes de sus talleres, o de aquellos pintores que les siguieron de cerca. Una tarea en este sentido, es la que realiza actualmente la doctora Elisa Vargas Lugo, a través de un Seminario de arte colonial: bajo su dirección se prepara un inventario minucioso de la obra del pintor Juan Correa.

De algunos artistas que estuvieron activos en la primera mitad del siglo xvir, sólo existen noticias aisladas, más algunos cuadros que se Jocalizan en diversos lugares del país. Uno de ellos es Basilio de Salazar, de quien hay obras fechadas en 1637 y 1645, entre ellas hay una por la cual bien se le podría calificar de maestro distinguido, o "afamado", como se le llamó en su época.

Poco es lo que se sabe sobre Basilio de Salazar, noticias suyas no las hay en España; no lo registra el clásico Diccionario de Agustín Céan Bermúdez, ni el de las Adiciones que le escribiera el conde de la Viñaza. En consulta hecha a Diego Angulo fñiguez, la contestación fue "... no hay datos de él". Las únicas noticias novoespañolas que existen, provienen de un posible contemporáneo suyo, el cronista franciscano fray Agustín de Vetancourt, quien escribió en su Crónica de la Provincia del Santo Evangelio de México las siguientes líneas, merced a las cuales nos informamos de la existencia de cuadros suyos que debieron contar cntre los más importantes de su producción: los pintados para el reta- 
blo mayor de la antigua iglesia de los franciscanos de México. He aquí lo que escribió Vetancourt:

La iglesia tiene un hermoso retablo dorado en el altar mayor, de obra mosaica (sic) y corintia, con diez y seis santos de talla entera que entre las columnas le acompañan, tableros de mano del afamado Basilio, de los misterios de Cristo y de su madre; en medio está una hermosa imagen de N.P.S. Francisco y otra más arriba de la Concepción de Nuestra Señora y un Santo Cristo en el tercer cuerpo. ${ }^{1}$

Lamentamos que el cronista no haya sido más prolijo en su descripción, por ejemplo, en lo tocante al tema de cada cuadro.

¿Fue Basilio de Salazar un pintor de origen americano? ¿Vino de España? Son preguntas sin respuesta; lo que sí se puede afirmar es que él fue contemporáneo de un importante grupo de maestros como Luis Juárez y su hijo José, de Baltasar de Echave Ibía, de Pedro Ramírez y Sebastián de Arteaga. Otras noticias no sobre la vida y actividades de Salazar, sino referentes a la localización de obras suyas, se deben a Agustín Fernández Villa, Manuel Toussaint y Francisco de la Maza. ${ }^{2}$ Esas noticias nos permiten formar hoy un breve inventario de cuadros e intentar un estudio de este pintor poco o nada conocido.

1. Retrato del arzobispo Juan Pérez de la Serna. Óleo sobre tela. $1.86 \times 1.12$ metros. Paradero desconocido.

2. Extasis de San Francisco. Óleo sobre tela. $1.05 \times 0.93$ metros. Museo de Guadalupe, Zacatecas.

3. San Diego de Alcalá. Atribuido. Óleo sobre tela. $0.97 \times 0.73$ metros. Museo de Guadalupe, Zacatecas.

4. Cristo en la cruz. Oleo sobre tela. Antigua colección Salvador Ugarte. México.

5. Exaltación franciscana de la Inmaculada Concepción, 1637. Oleo sobre tela. 1.17 x 0.95 metros. Museo Regional. Querétaro. Qro.

1 Tomo III, p. 120. México, 1967.

2 Agustín Fernández Villa, Breves apuntes sobre la antigua escuela de pintura en México. Y algo sobre la escultura, p. 88. México, 1919. Manuel Toussaint: Pintura colonial en México, p. 83. Instituto de Investigaciones Estéticas. México, 1965. Francisco de la Maza, "Las pinturas del Museo de Guadalupe en Zacatecas", Caminos de México, núm. 23, sin paginación. México, 1956. 
6. La Misa de San Gregorio, 1645. Oleo sobre tela. $1.61 \times 1.26$ metros. Oratorio de San Felipe Neri. León, Guanajuato.

Ante el estudio de estas telas de Basilio de Salazar, lo primero que salta a la vista es la dispareja calidad que existe en ellas. El problema, por cierto, no es adjudicable únicamente a este pintor, en realidad esa ausencia de calidad uniforme se encuentra en la mayoría de los artistas que trabajan a lo largo de los siglos xviı y xvm, un poco a la sombra de maestros dueños de una labor sobresaliente, verbigracia, un José Juárez. Algunos pintores que procedían de España allá no eran sino mediocres oficiales de los grandes obradores establecidos, por ejemplo, en Andalucía, aquí encontraron un ambiente más propicio tanto para trabajar como para alcanzar fácilmente una fortuna económica.

El retrato del arzobispo Pérez de la Serna, se exhibía en lo que fue el Museo de Arte Religioso, instalado en la Capilla de las Ánimas, situada en el ámbito de la Catedral Metropolitana. ${ }^{3}$ La pintura desapareció inexplicablemente cuando el tesoro artístico de la catedral, que era la base del museo, fue trasladado a Tepotzotlán para formar lo que hoy en día es el Museo Nacional del Virreinato.

El retrato de Pérez de la Serna, es una obra importante en la producción de Basilio de Salazar, pues nos lo muestra en un género que seguramente manejaba con frecuencia, el de retratista, según puede deducirse de otra tela suya que aqui se reproduce (figuras 7 y 8 ). El cuadro no estaba fechado y no se sabe por consiguiente, si el artista lo pintó directamente ante el modelo, o si lo hizo a posteriori según costumbre; es decir, si lo realizó entre 1613 y 1625, años del gobierno episcopal de Pérez de la Serna. o cuando éste había dejado su alta investidura. Carrillo y Gariel sitúa la fecha hacia 1614, para Toussaint en cambio, fue pintado después de 1625 .

Pero hay algo más en relación con el retratado, pues él mucho tuvo que ver con los pintores por una situación que se antoja imposible en la moral de los habitantes de la capital del virreinato hacia la primera mitad del siglo xvil, época en la cual la Inquisición estaba al pendiente de todo aquello que olía a relajamiento de las conciencias y costumbres. De

3 Aflí lo vieron Manuel Toussaint y Abelardo Carrillo y Gariel quien tomó las. medidas del cuadro e hizo una calca de la firma, la que rezaba así: Basilio de Salazar F., está reproducida en su libro Autógrafos de pinturas coloniales, segunda edición, p. 104. Instituto de Investigaciones Estéticas, UNAM. México, 1972. 
los hechos sobresalientes de la actuación de Pérez de la Serna, se ha prestado mayor atención al grave conflicto que tuvo con el virrey Marqués de Galves, olvidándose del edicto que promulgara en 1618 en contra del libertinaje en que habian caído los habitantes de la ciudad, en una época de "mundo cerrado", en el cual se ejercía un control absoluto sobre las actividades vitales del hombre. Tal situación deja entrever un estado de cosas que contrasta con la visión id́lica de las costumbres que se desprende de las obras literarias de Bernardo de Balbuena y Arias de Villalobos. Respecto a los pintores, el arzobispo se encontró durante una visita general que hizo dentro de su jurisdicción, que éstos hacían "las imágenes más torpes y abominables que se puedan imaginar". Le incomodó la costumbre de pintar cuadros religiosos al gusto de quienes hacían el encargo o al capricho de los pintores. Para acabar un tal estado de cosas recordó lo estipulado en la Sección XXV del Concilio de Trento. La situación que tanto le alarmó es la que en seguida se transcribe:

... se pintan historias apócrifas y en otras mentirosas, y que la disolución y licencia de los pintores había llegado a tanto, que hacían retratos de amancebadas y devotos, disimulándolos con insignias de santos y santas, teniéndolas en esta forma en sus casas y aposentos... (por lo cual dispuso mediante un edictci) que todas las imágenes sagradas se registrasen, y que para adelante no se pudieran tener sin que un pintor de práctica y experiencia las aprobase, y que esta aprobación y examen se hiciese de balde; y habiéndo comenzado a descubrirse muchas imágenes indecentes a petición de un pintor malo que ha dado en hacer pinturas ridículas y de poca autoridad, como de un Niño Jesús caballero sobre un cordero, corriendo con una veletilla de niños en una mano, y un pájaro atado de una cuerda en otra, y otras a este tono...4

En la pinacoteca instalada en lo que fue el colegio franciscano de Propaganda Fide, en Guadalupe, Zacatecas, se exhiben dos telas de Basilio de Salazar. Una de ellas está firmada, mas carece de fecha, el tema de que se ocupa es el Extasis de San Francisco. La otra representa a San Diego de Alcalá, carece tanto de firma como de fecha, en realidad creo que se trata de una adjudicación sin fundamento serio. Ambos cuadros tienen algo en común: son fragmentos de obras mayores de las cuales

4 "Documentos relativos al tumulto de 1624, colectados por don Mariano Fernández de Echeverria y Veitia", en Documentos para la historia de México, segunda serie, t. II, p. 12. México, 1855. 
únicamente se salvaron las imágenes titulares. El Extasis de San Francisco, nos muestra a Basilio de Salazar como un pintor punto menos que mediocre, tanto la figura del santo de Asís, como las de los ángeles que la auxilian, aś́ lo demuestran. Quizá la parte mejor lograda sea la del rostro de San Francisco, pese a lo convencional de su realismo. Fsta observación es aplicable al San Diego de Alcalá, la nota sobresaliente del cuadro se encuentra en la cabeza del santo, está bien modelada por las luces y sombras que tiene; este cuadro no es sino una interpretación iconográfica más, de un tema tratado en España por Francisco de Zurbarán y en la Nueva España por José Juárez (figuras 2 y 3 ).

El Cristo en la cruz, de paradero hoy desconocido, debe ser una de las buenas obras que trabajó Basilio de Salazar, a juzgar por la fotografía que aquí se publica (figura 4). El pintó ese cuadro dentro del gusto tenebrista de la época, si bien la composición no le es original del todo, pues el mostrar únicamente la parte superior del cuerpo de Jesucristo, sin brazos, tiene sus antecedentes en la pintura española, pienso, por ejemplo, en Luis de Morales. Encuentro en las obras de Basilio de Salazar una constante que bien pudiera servir para identificar otras telas suyas; la constante se refiere a esa tendencia de modelar los rostros miediante contrastes acentuados de luz y sombras, recurso que le permitió dar esa expresión de dolor y ascetismo; mediante un hábil manejo de la pasta pudo modelar los rostros con singular efecto, tanto en los pómulos como en el hundimiento de las cuencas de los ojos. Si se observan los cuadros aquí reproducidos, y en particular este Cristo en la cruz, se puede advertir la existencia de una constante en la producción de este maestro del siglo xvir.

Resulta aventurado hablar sobre una obra de arte que no se conoce, respecto a este Cristo de Basilio de Salazar guardo las siguientes reservas: ¿se trata de un cuadro completo, o bien, como en otros casos, es solamente fragmento de una tela mayor? La pintura tiene una ténue cortina que cubre parte de la imagen, ¿era ésta objeto de una devoción particular entre los fieles para quienes fue hecha? Nada en firme se puede contestar, salvo lo dicho con anterioridad: posiblemente este cuadro figure entre lo mejor que de su autor ha llegado a nosotros.

El cuadro de la Exaltación franciscana de la Inmaculada Concepción, se encuentra en deplorable estado de conservación; la firma del pintor está dividida en dos secciones de la tela y ostenta la fecha de 1637. 
DOI: http://dx.doi.org/10.22201/iie.18703062e.1976.46.1054

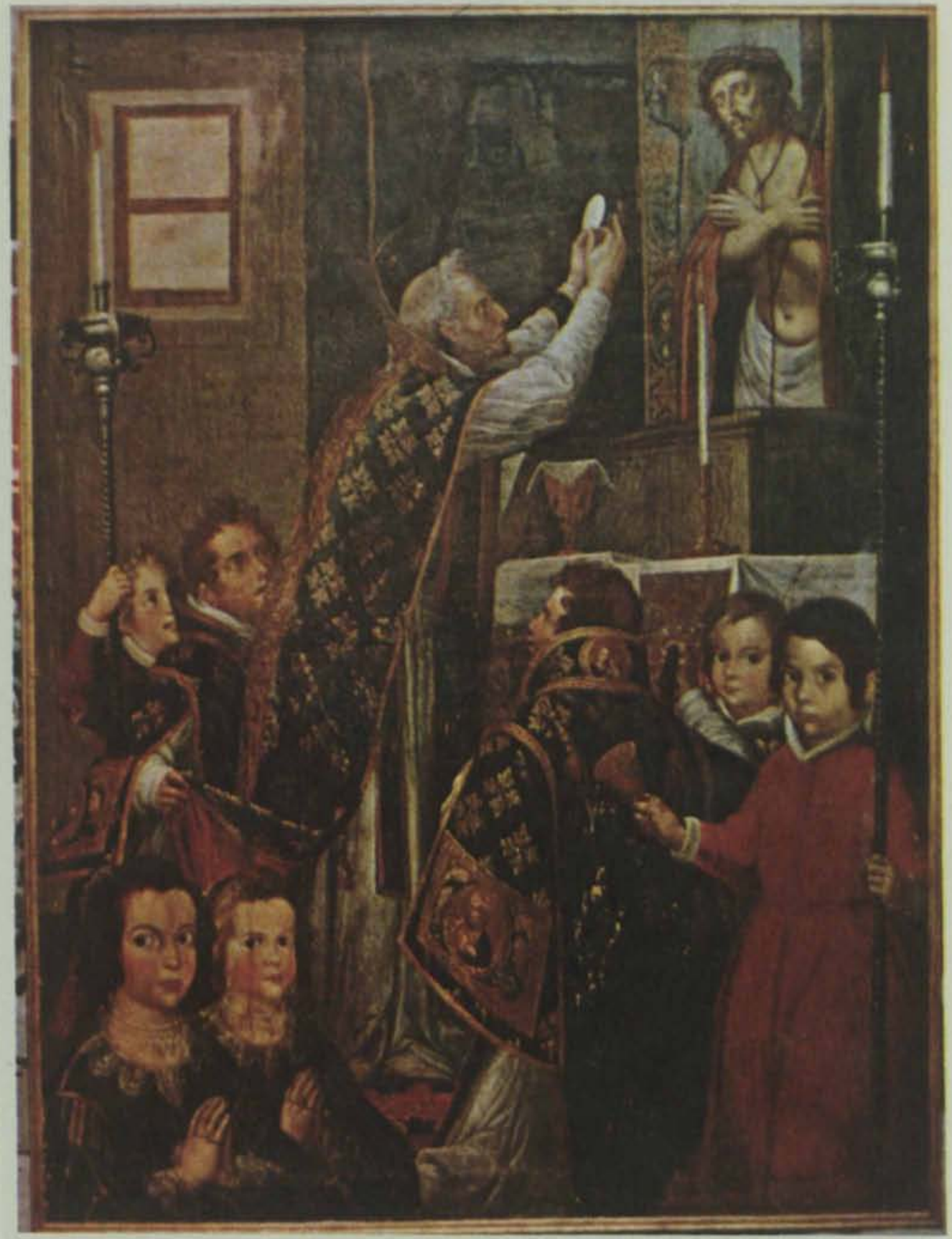

Figura 1. Basilio de Salazar. La misa de San Gregorio. 1645. 
DOI: http://dx.doi.org/10.22201/iie.18703062e.1976.46.1054

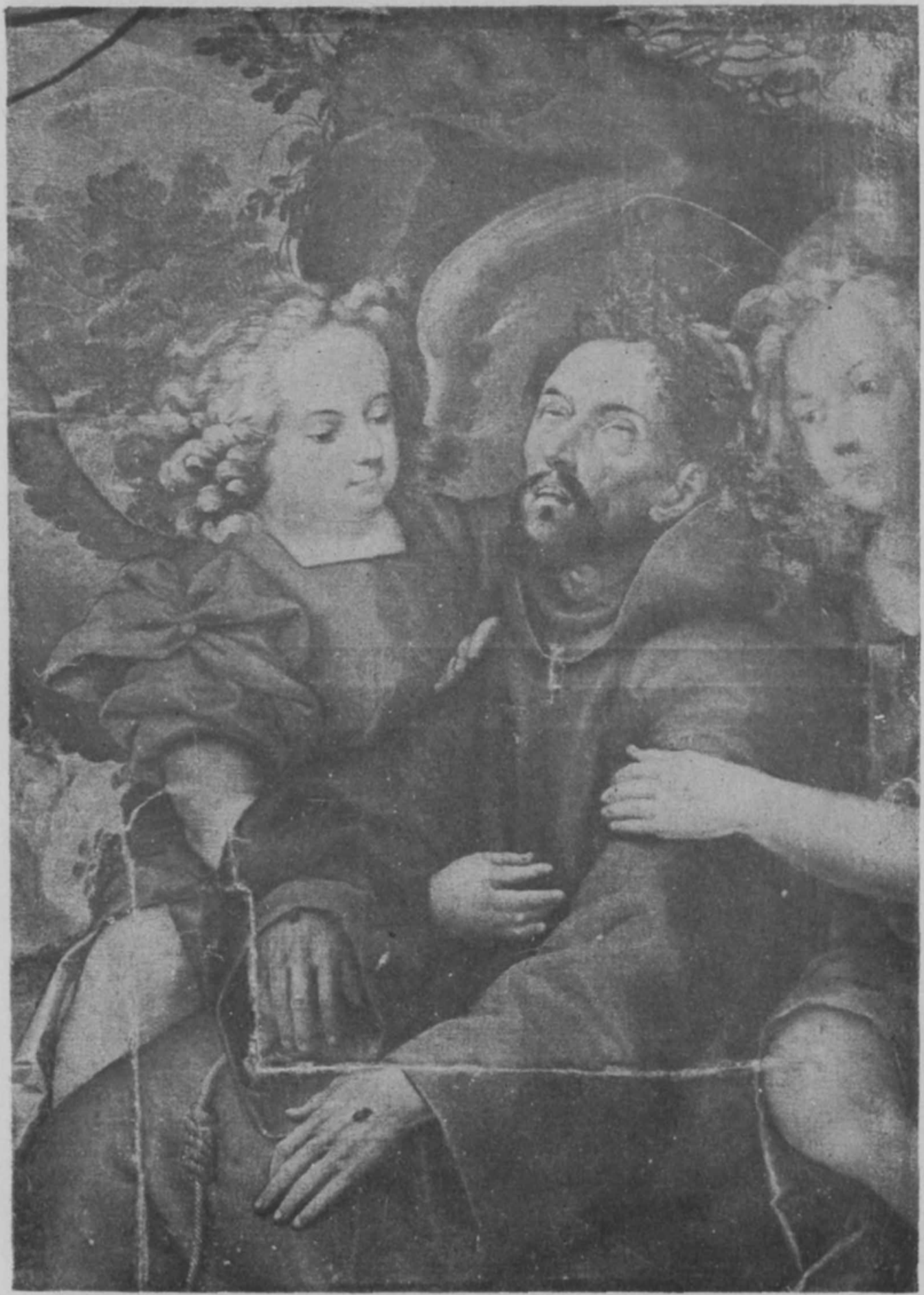

Figura 2. Basilio de Salazar. Extasis de San Francisco. 
DOI: http://dx.doi.org/10.22201/iie.18703062e.1976.46.1054

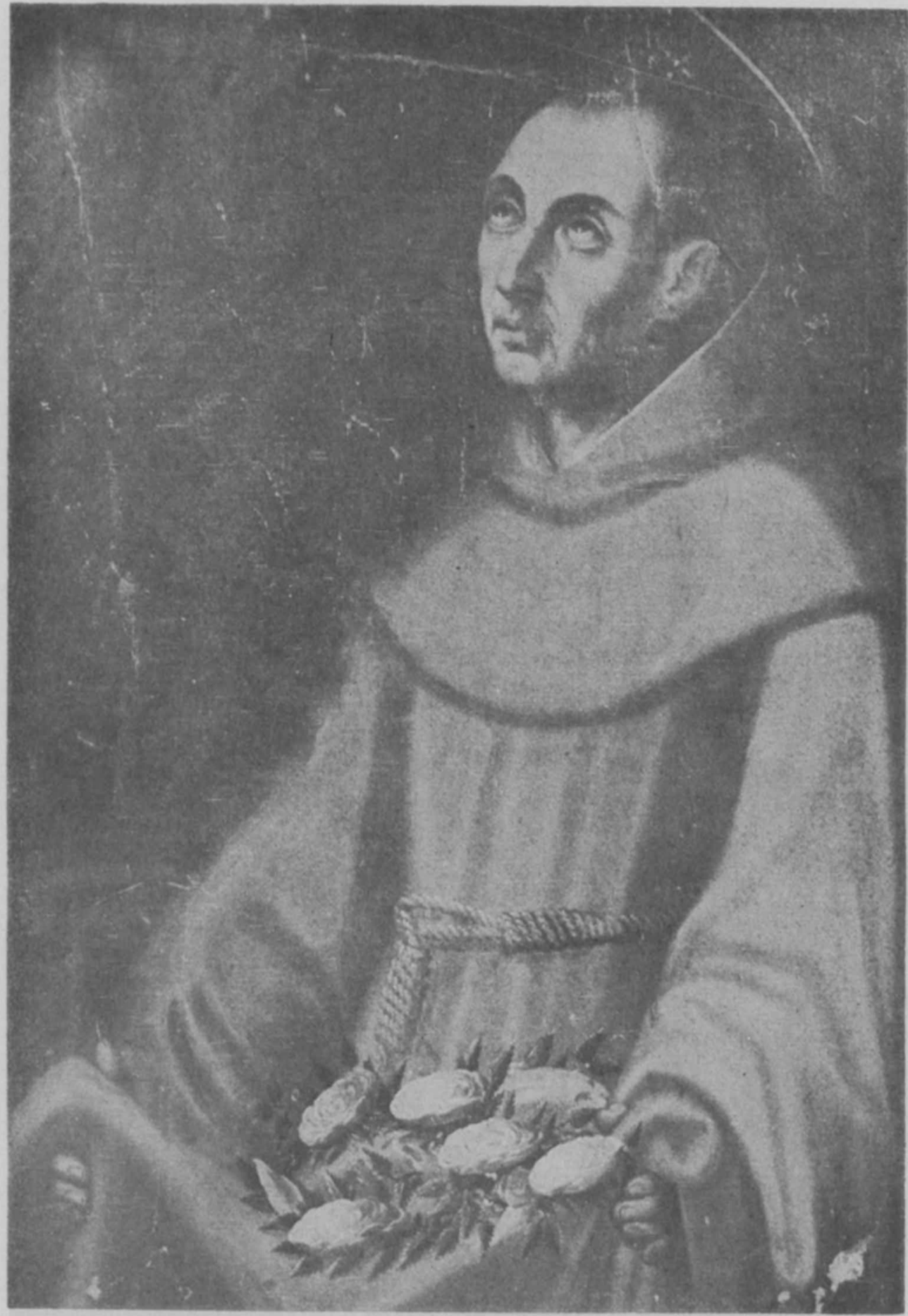

Figura 3. Basilio de Salazar. San Diego de Alcalá. 


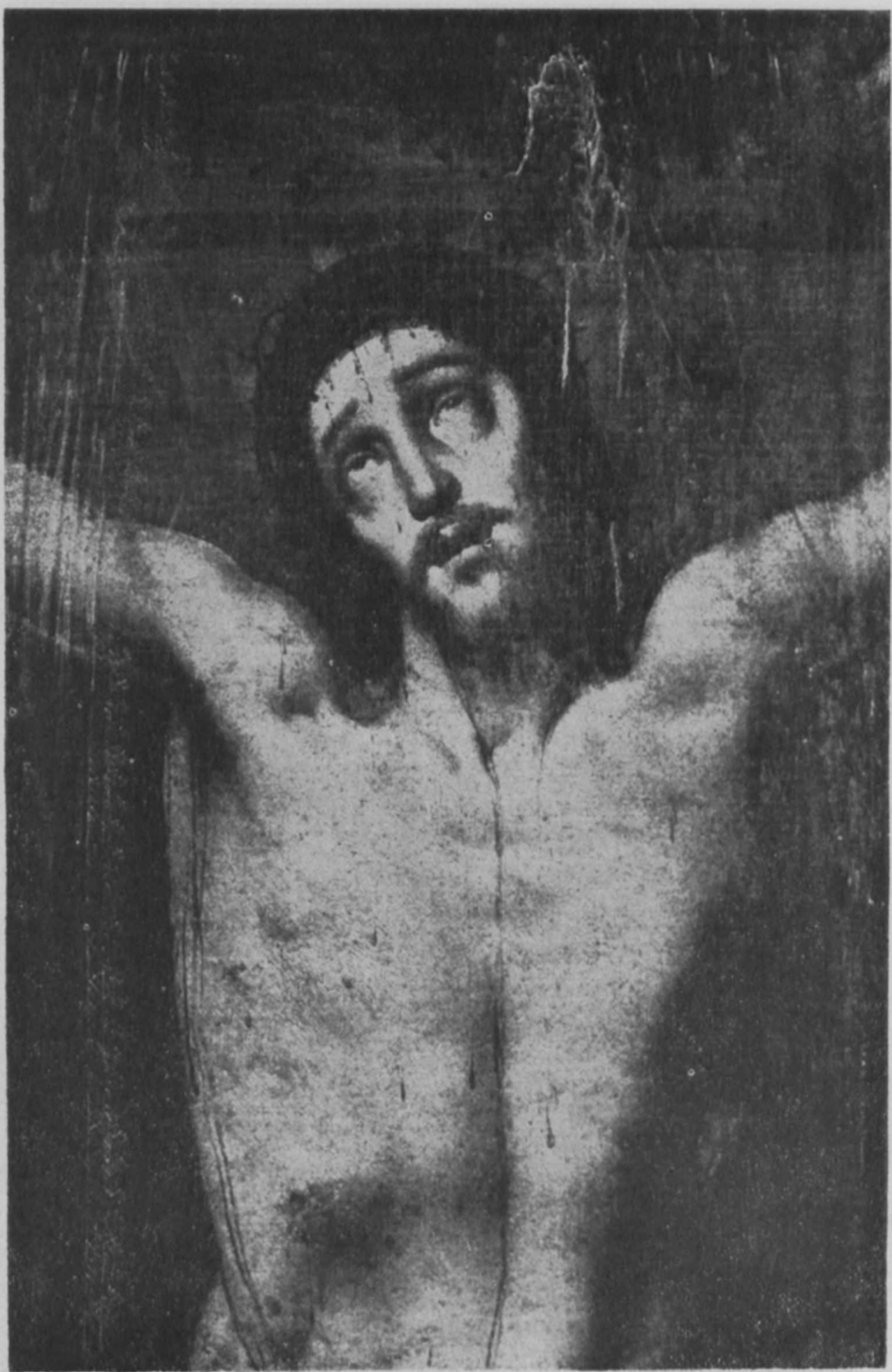

Figura 4. Basilio de Salazar. Cristo en la cruz. 
DOI: http://dx.doi.org/10.22201/iie.18703062e.1976.46.1054

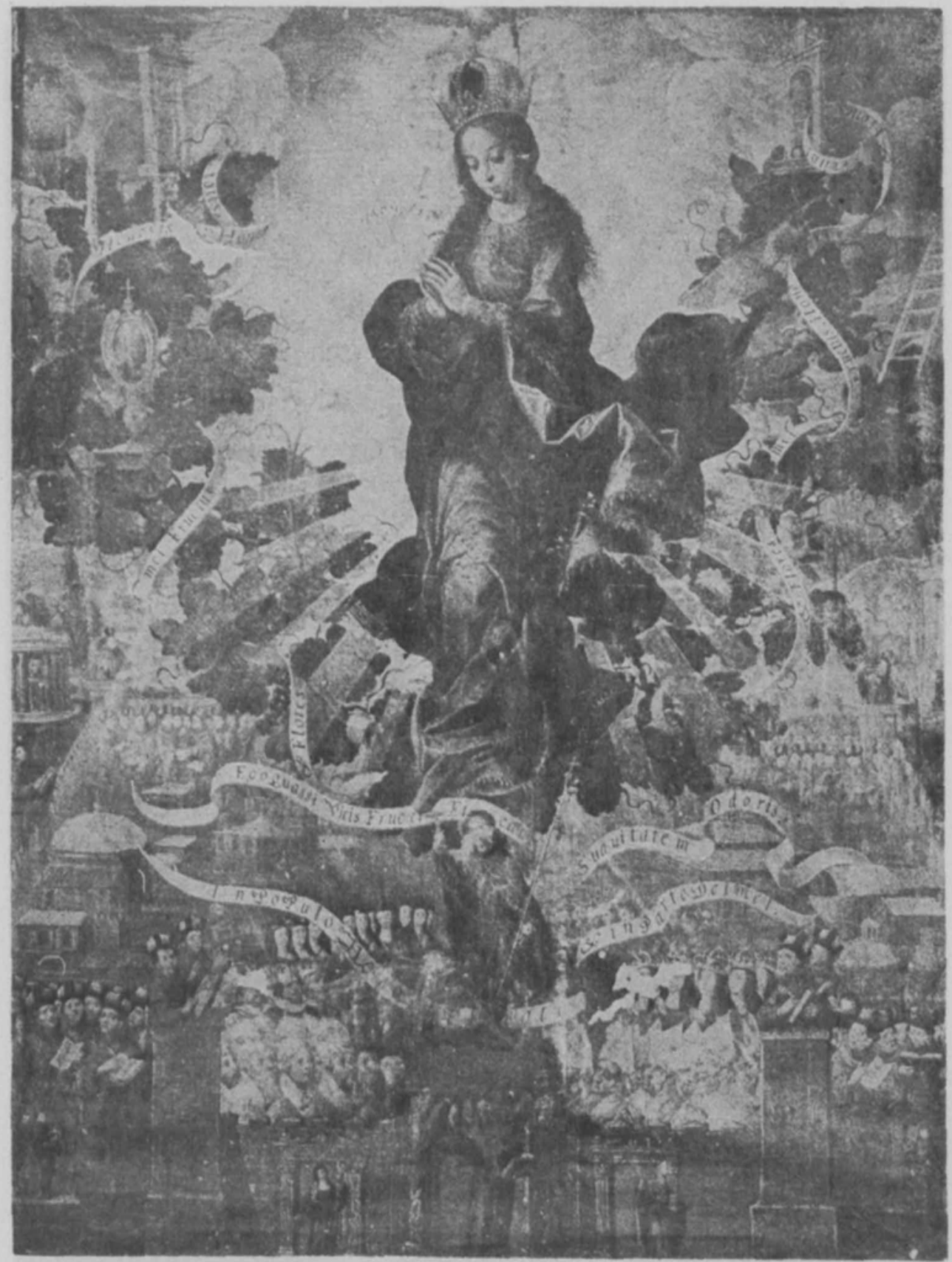

Figura 5. Basilio de Salazar. Exaltación franciscana de la Inmaculada Concepción. 1637. 
DOI: http://dx.doi.org/10.22201/iie.18703062e.1976.46.1054

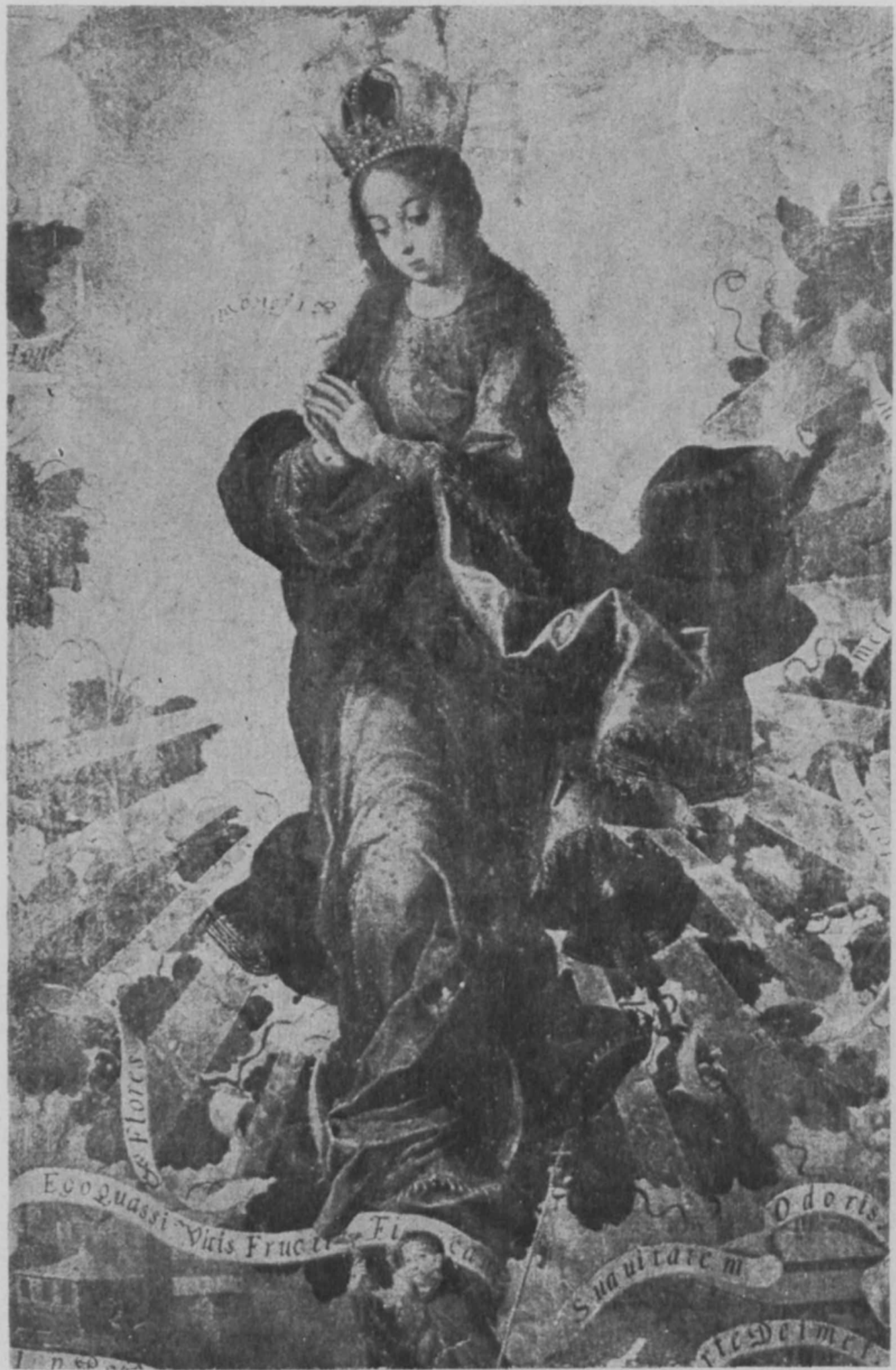

Figura 6. Exaltación franciscana de la Inmaculada Concepción. Detalle. 
DOI: http://dx.doi.org/10.22201/iie.18703062e.1976.46.1054

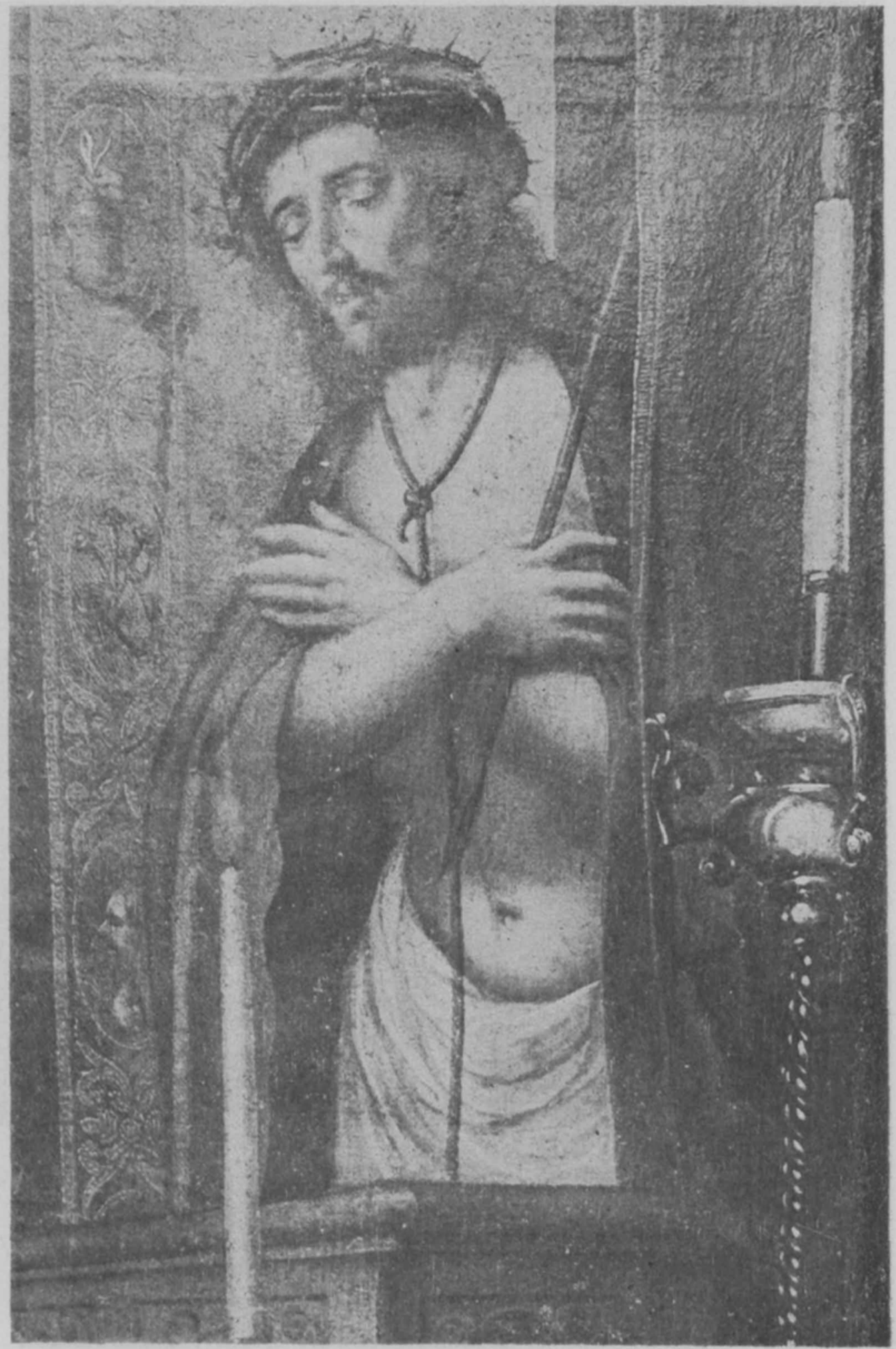

Figura 7. Basilio de Salazar. La Misa de San Gregorio. Detalle. 


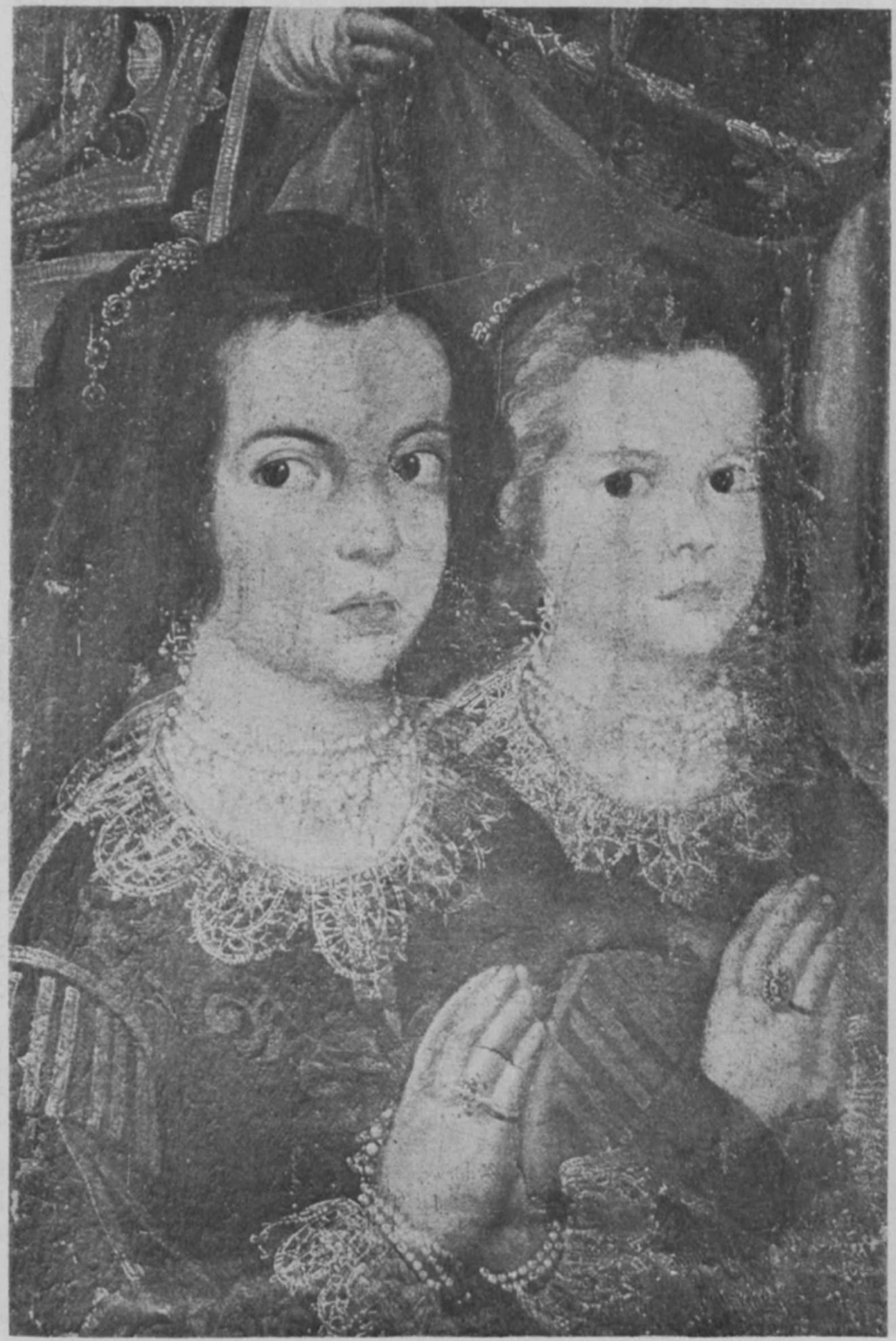

Figura 8. Basilio de Salazar. La Misa de San Gregorio. Detalle. 
DOI: http://dx.doi.org/10.22201/iie.18703062e.1976.46.1054

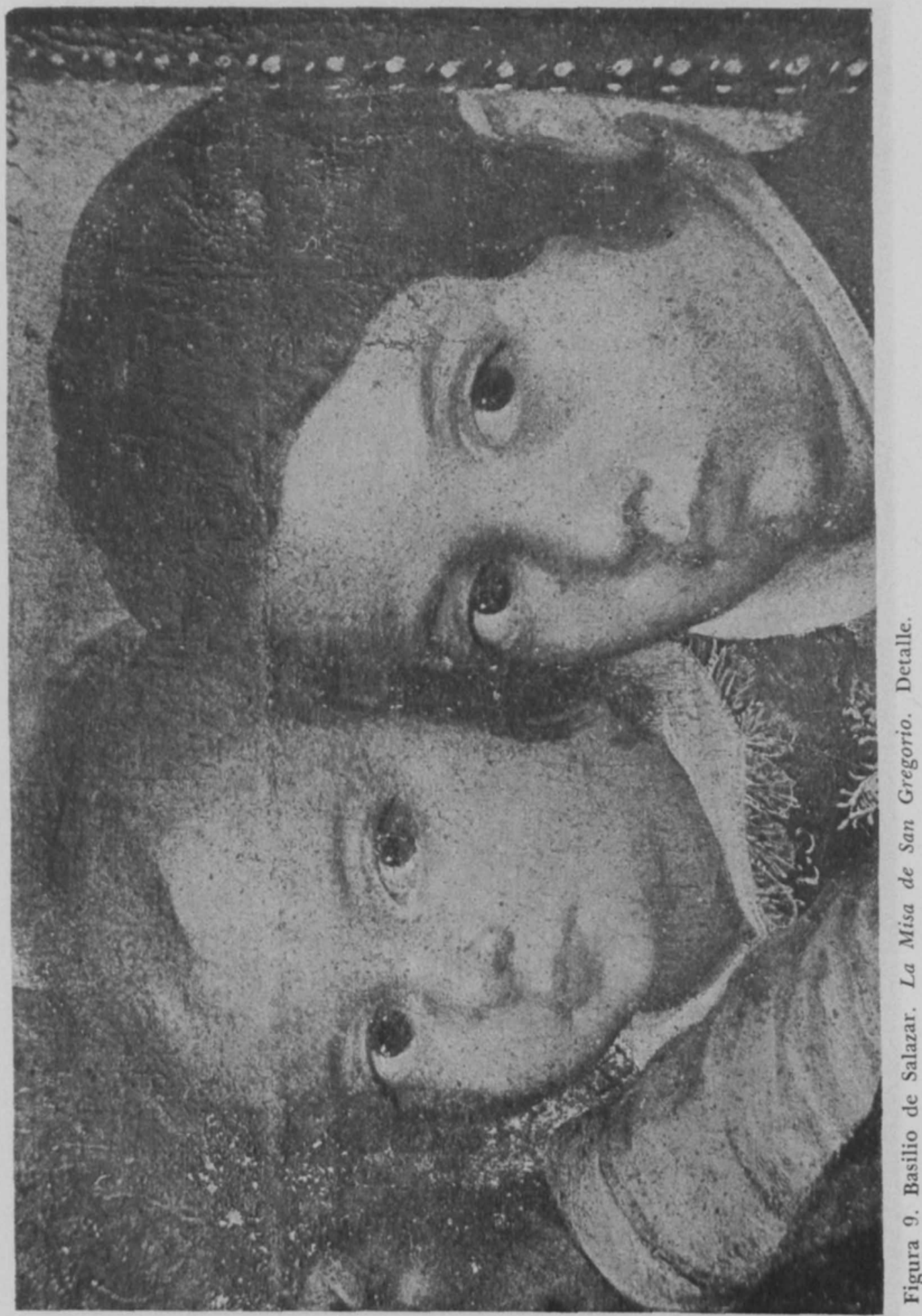


Como obra de arte es de una medianía que raya en la mediocridad y cuesta trabajo el aceptar que la haya pintado el mismo artista, que ocho años más tarde firmara la tela de La Misa de San Gregorio. Se trata de una obra aparatosa y fallida, sobre todo en la parte inferior en donde aparecen como míseras figuras, las de los apologistas que ha dado la orden franciscana en defensa del dogma de la pureza de Maria. Es inaceptable esta parte de la pintura, tan falta de perspectiva, de dibujo y composición. La imagen de la Virgen está llena de ese movimiento agitado tan caro al gusto de los pintores barrocos, mas su factura es torpe y desproporcionada. Le rodean los símbolos de sus atributos, colocados como los religiosos franciscanos, entre movidas filacterias que afirman con sus leyendas, el dogma que representa y exalta esta pintura (figuras 5 y 6 ).

El origen de la composición de este cuadro debe encontrarse en una de tantas láminas que los artesanos flamencos grabaron en favor del movimiento contrarreformista, ${ }^{\circ}$ estampas que circulaban profusamente tanto en España como en sus dominios americanos; toda la composición indica ese origen, desde la imagen de la Purísima y las filacterias que aiuden a sus atributos, hasta las figuras de cerrada y torpe disposición que están en la parte inferior. Obras como ésta son de devoción dogmática $y$, por consiguiente, ajenas a la creación artística.

Con una composición cerrada y tupida de figuras, Basilio de Salazar se nos presenta, en cambio, como un maestro digno de consideración en su cuadro La Misa de San Gregorio, cuadro que es, acaso, el mejor que de él habremos de conocer. ¡Cuán lejos se halla de las telas anteriores! Aquí sí se justifica el juicio del cronista Vetancurt, quien lo calificó del pintor "afamado". El tema de la Misa de San Gregorio, surgido en la Edad Media, favoreció la creación de una amplísima iconografía a la cual contribuyó el arte del siglo xvi de la Nueva España. ${ }^{*}$

En el eje central del cuadro destaca la figura, magnifica y solemne, de San Gregorio; está representado en el momento culminante en el que al elevar la Sagrada Forma, se le aparece Jesucristo. En la imagen de

- Un aspecto poco difundido en la historia del arte de la Contrarreforma, es el que corresponde a la aportación que a tal fin hicieron los artistas flamencos. Sobre este tema se recomienda el estudio del excelente trabajo de John B. Knipping, lconographi of the counter reformation in the netherlands. 2 volumenes. B. de Graaf - Nienwkoop / A. W. Sijthoff, 1974.

- Asf lo ha comprobado Mariano Monterrosa en su estudio de las cruces atriales. Obra de inaplazable publicación por las sugerentes aportaciones en ella contenidas. 
éste, el pintor alcanzó uno de sus mejores momentos de inspiración religiosa y realización artística. La invariante advertida en la producción de De Salazar, se muestra aquí en la esmerada factura del rostro de Jesucristo. Bien proporcionada y pintada es también la figura del diácono que aparece en primer término (figura 1).

Es evidente que el tema de la tela es el de la Misa de San Gregorio; sin embargo, bien se puede decir que ésta ha sido pintada con una intención que va más allá de lo específicamente religioso para referirse a lo mundano en primer término. Dígalo si no, el número de retratos. que hay en ella, seis por lo menos, siendo los principales los de los niños que Basilio de Salazar dispuso en los extremos de la tela en función de donantes. Como un retratista nada despreciable se muestra en los retratos de las dos jovencitas que colocó en el ángulo inferior izquierdo (figura 8). Sus lindos y enormes ojos están muy lejos de la devoción, están dirigidos hacia un objeto que se encuentra frente a ellos. Por otra parte, hay una ostentación manifiesta de riqueza y poder en las. vestimentas y alhajas que portan, signo evidente de una sociedad próspera y mundana.

Retratos son, asimismo, los de los niños que aparecen en el otro extremo, vestidos de monaguillos (figura 9). Como en el caso de las jovencitas no ven hacia el frente, dirigen la mirada hacia el mismo punto, en donde se encontraba un posible espectador atento al desarrollo de la pintura. Los rostros de los niños fueron modelados con amor, con gusto, con interés de hacer un arte naturalista más allá de la pura devoción religiosa. Retratos también parecen ser tanto el del segundo diácono como el del monaguillo, ambos se localizan atrás de San Gregorio. En conclusión, Basilio de Salazar se nos muestra en esta obra como un hábil y sensible retratista, digno de atención y estudio.

Ésta es la obra hasta hoy identificada de Basilio de Salazar. Manuel Toussaint registró una Predicación de San Francisco, existente en el Museo Regional de Guadalajara, cuadro que se volvió ojo de hormiga como el retrato del arzobispo Pérez de la Serna. A través de sus telas conocidas Basilio de Salazar se nos muestra como un artista menor entre el grupo de maestros que constituyen lo que se ha llamado el "Siglo de Oro" de la pintura virreinal. Él representa, en cierta forma, un tipo de producción que con frecuencia cayó en lo artesanal debido a la gran demanda originada en un momento en que las condiciones económicas de la Iglesia estaban sólidamente constituidas y ofrecían un inmenso 
campo de trabajo. En realidad todo obedecía a que la estructura sobre la que iba a descansar el virreinato estaba ya bien definida y asentada en esa época, en la que ya se había iniciado el proceso formativo de una conciencia sobre lo que era este país, dentro del imperio español de ultramar, con los escritos de un Bernardo de Balbuena y un Arias de Villalobos.

En el arte de la Nueva España, Basilio de Salazar ocupó un sitio secundario, asi lo veo, dentro del engranaje que formaban los artistas sobresalientes de la primera etapa del barroco. ¿Pero hasta dónde llega la validez de estos juicios? No he parado mientes en calificarle de buen retratista, además existe el hecho de que únicamente se conoce una parte insignificante de lo que debió ser, en su caso, una extensa producción. Dejemos hasta aquí las cosas hasta que no se identifiquen, si ello es posible, otras pinturas suyas. ${ }^{7}$

7 Agradezco a la profesora María Esther Siancas de Jiménez Moreno, la noticia de la existencia del cuadro La Misa de San Gregorio. Las fotografías 1, 5, 6, 7, 8 y 9 se deben a las profesoras Amada Martínez y Guillermina Vázquez, encargadas de la Fototeca de este Instituto; las que llevan los números 2 y 3 son una cortesía de Federico Sescosse. 